\title{
Genetic Pathways of Neuroregeneration in a Novel Mild Traumatic Brain Injury Model in Adult Zebrafish
}

(1) Amanda L. Maheras, ${ }^{1,3}$ Brian Dix, ${ }^{2,3}$ (D) Olivia M. S. Carmo, ${ }^{2,3}$ (D)Aleena E. Young, ${ }^{2,3}$ Vanessa N. Gill, ${ }^{2,3}$ (D) Julia L. Sun, ${ }^{1,3}$ Aleah R. Booker, ${ }^{1,3}$ Helen A. Thomason, ${ }^{1,3}$ Anastasia E. Ibrahim, ${ }^{2,3}$ Lauren Stanislaw, ${ }^{1,3}$ Jennifer C. Dallego, ${ }^{2,3}{ }^{-}$Cat N. Ngo, ${ }^{3,4}{ }^{-}$Audrey Chen, ${ }^{5}{ }^{-}$Barbara K. Fortini, ${ }^{6}$ and Rory D. Spence ${ }^{3}$

DOI:http://dx.doi.org/10.1523/ENEURO.0208-17.2017

${ }^{1}$ Scripps College, Claremont, CA 91711, ${ }^{2}$ Claremont McKenna College, Claremont, CA 91711, ${ }^{3}$ Keck Science Department, Claremont, CA 91711, ${ }^{4}$ Harvey Mudd College, Claremont, CA 91711, ${ }^{5}$ Ayala School of Biological Sciences, Department of Neurobiology \& Behavior, University of California, Irvine, Irvine, CA, and ${ }^{6}$ School of Pharmacy, Keck Graduate Institute, Claremont, CA 91711

\section{Visual Abstract}
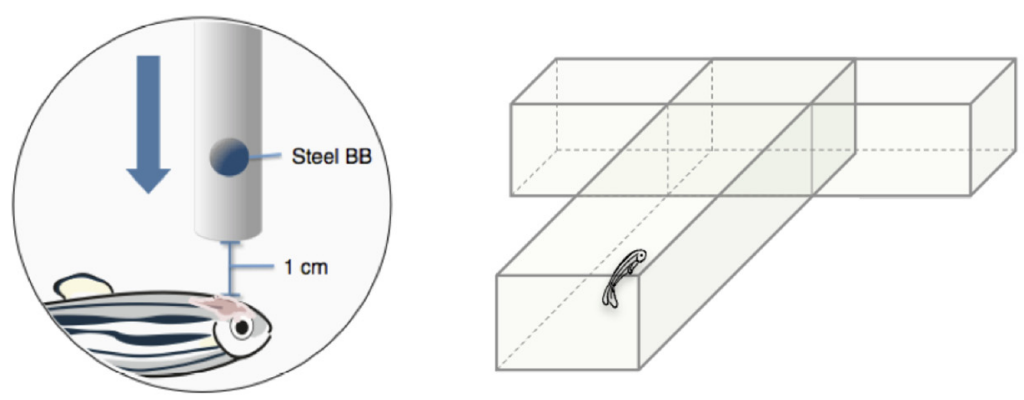

Behavioral Test

Weight Drop

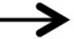

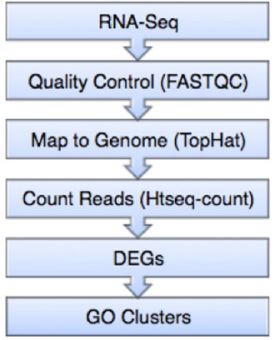

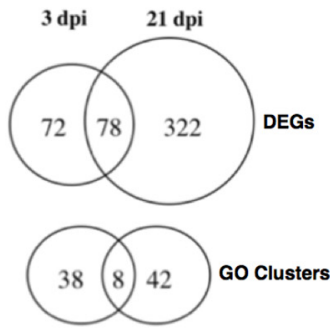

RNA-Seq Analysis

Mild traumatic brain injuries (mTBls) are one of the most prevalent neurological disorders, and humans are severely limited in their ability to repair and regenerate central nervous system (CNS) tissue postinjury. However, zebrafish (Danio rerio) maintain the remarkable ability to undergo complete and functional neuroregeneration as an adult. We wish to extend knowledge of the known mechanisms of neuroregeneration by analyzing the differentially expressed genes (DEGs) in a novel adult zebrafish model of mTBI. In this study, a rodent weight drop

\section{Significance Statement}

Mild traumatic brain injuries (mTBIs) are a major health concern in the United States, with $\sim 2.8$ million concussions reported annually by the CDC. Despite increased awareness within the last decade of the dangers surrounding mTBls, incidence of concussions continues to rise. Humans are extremely limited in their ability to repair their brain after an injury such as a concussion. To better understand this issue, we developed a novel mTBI model in adult zebrafish. Our model is inexpensive and easily adaptable for other researchers. Much like humans, zebrafish brains undergo an injury response after an injury. Unlike humans, zebrafish maintain the remarkable ability to regenerate and repair their brain after a concussion. We have analyzed the neural pathways involved in zebrafish brain regeneration. These data provide critical insight into the processes of neural repair in zebrafish and will contribute to a better understanding in the scientific community of neuroregeneration. 
model of mTBI was adapted to the adult zebrafish. A memory test showed significant deficits in spatial memory in the mTBI group. We identified DEGs at 3 and 21 days postinjury (dpi) through RNA-sequencing analysis. The resulting DEGs were categorized according to gene ontology (GO) categories. At $3 \mathrm{dpi}$, GO categories consisted of peak injury response pathways. Significantly, at $21 \mathrm{dpi}$, GO categories consisted of neuroregeneration pathways. Ultimately, these results validate a novel zebrafish model of $\mathrm{mTBI}$ and elucidate significant DEGs of interest in CNS injury and neuroregeneration.

Key words: Concussion; DEG; mTBI; RNA-seq; TBI; zebrafish

\section{Introduction}

Traumatic brain injuries (TBIs) are a leading health concern in the United States, contributing to $30 \%$ of all reported injury-related deaths. In 2010, there were $\sim 2.5$ million reported cases of TBI in the United States, either from an isolated injury or concurrent with other trauma (Taylor et al., 2017). These numbers are assumed to be grossly underestimated, as many injuries are likely not being reported and/or individuals are not seeking care (Corrigan et al., 2010). An increasing amount of investigation has focused on the occurrence, pathophysiology of initial and secondary injuries, and recovery process of TBls (Boyle et al., 2014; Taylor et al., 2017). As a result, TBls are now being treated more as a disease than as a traumatic event (Masel and DeWitt, 2010), including mild TBI (mTBI), more commonly known as a concussion. Initial symptoms of a mTBI may include loss of consciousness, amnesia, headaches, and nausea (Len and Neary, 2011), but in $30 \%$ of cases, persistent effects manifest into post-concussive syndrome (PCS; Lewine et al., 2007). Symptoms such as cognitive and memory impairments (Vanderploeg et al., 2005), as well as motor deficiencies (De Beaumont et al., 2007), can be long term. Pathologically, injuries can be either primary or secondary. Primary injuries occur at the time of the trauma and can include fracture, as well as an increase in pressure and bleeding. Secondary injuries occur after the traumatic event and may involve disruption in system function at the

Received June 13, 2017; accepted December 12, 2017; First published January 2, 2018.

The authors declare no competing financial interests.

Author contributions: A.L.M., B.D., A.C., B.K.F., and R.D.S. designed research; A.L.M., B.D., O.M.S.C., A.E.Y., V.N.G., J.L.S., A.R.B., L.S., J.C.D., C.N.N., A.C., B.K.F., and R.D.S. performed research; A.L.M., B.D., O.M.S.C., C.N.N., A.C., B.K.F., and R.D.S. analyzed data; A.L.M., B.D., O.M.S.C., H.A.T., A.E.I., A.C., B.K.F., and R.D.S. wrote the paper; R.D.S. contributed unpublished reagents/analytic tools.

Our funding was provided by start-up lab funds provided by the Keck Science Department. Student research support was provided by the Rose Hills Foundation, The Libby Faculty-Student Collaboration Fund, HHMI, and the Keck Science Department.

A.L.M. and B.D. contributed equally to this work.

Acknowledgments: We thank the Keck Science Department and Scripps, Pitzer, and Claremont McKenna College. We thank Marion R. Preest and David A. Prober for temporary use of their equipment and laboratory space. We also thank Melissa J. Coleman for her mentorship.

Correspondence should be addressed to Rory D. Spence, Office 124, Keck Science Department, 925 N. Mills Avenue, Claremont, CA 91711. E-mail: rory.spence@gmail.com.

DOl:http://dx.doi.org/10.1523/ENEURO.0208-17.2017

Copyright $\odot 2018$ Maheras et al.

This is an open-access article distributed under the terms of the Creative Commons Attribution 4.0 International license, which permits unrestricted use, distribution and reproduction in any medium provided that the original work is properly attributed. molecular and cellular level. This may be in the form of problems with neurotransmitter release and reuptake, scarring from astrocytes at the site of injury, inflammation, and necrosis and apoptosis of neuronal and glial cells (Mckee and Daneshvar, 2015).

Adult mammals have limited neuroregenerative capabilities after an injury to the central nervous system (CNS; Lieschke and Currie, 2007). Interestingly, zebrafish (Danio rerio) maintain the remarkable ability to regenerate and repair neural tissue throughout adulthood (März et al., 2011; Kishimoto et al., 2012; Skaggs et al., 2014). While some important mechanisms of zebrafish neuroregeneration have been identified (Kishimoto et al., 2012; Kyritsis et al., 2012), no one has examined the entire transcriptome of the adult zebrafish during neuroregeneration.

Current zebrafish TBI studies use stab or lesion models to induce injury (Kroehne et al., 2011; Kishimoto et al., 2012; Kyritsis et al., 2012; Skaggs et al., 2014). Although these models are novel for the analysis of focal injuries in the zebrafish brain, they could be considered moderate or severe models of $\mathrm{TBI}$, as they both involve penetration from the epidermal layer through the blood-brain barrier (Saatman et al., 2008). Here, we adapted a novel mTBI model for zebrafish by applying modifications to an accepted rodent weight drop apparatus (Mychasiuk et al., 2014). Our model inflicts a nonpenetrating, diffuse mTBI injury that allows for the study of the entire zebrafish brain transcriptome during neuroregeneration.

The purpose of this study was twofold: first, to develop a model of mTBI using adult zebrafish; and second, to elucidate the genetic pathways of the adult zebrafish during the peak injury response and the peak of neuroregeneration. To do so, we examined differential gene expression in adult zebrafish at 3 days postinjury (dpi), which corresponded to the peak injury response and a significant deficit in spatial memory, and $21 \mathrm{dpi}$, the estimated peak neuroregeneration response, in comparison to sham controls that did not receive an mTBI. We then collected data using RNA-sequencing (RNA-seq) followed by transcriptome analysis. Each time point was compared to sham controls to identify differentially expressed genes (DEGs) and affected gene ontology (GO) clusters in biological processes, cellular components, and molecular functions.

\section{MATERIALS AND METHODS}

\section{Animals}

All animals used were commercially acquired adult zebrafish (Danio rerio), homozygous with lof ${ }^{\mathrm{dt2}}$, a long-fin mutation. The fish were maintained in accordance with standard protocol on a 14-h/10-h light/dark schedule at 


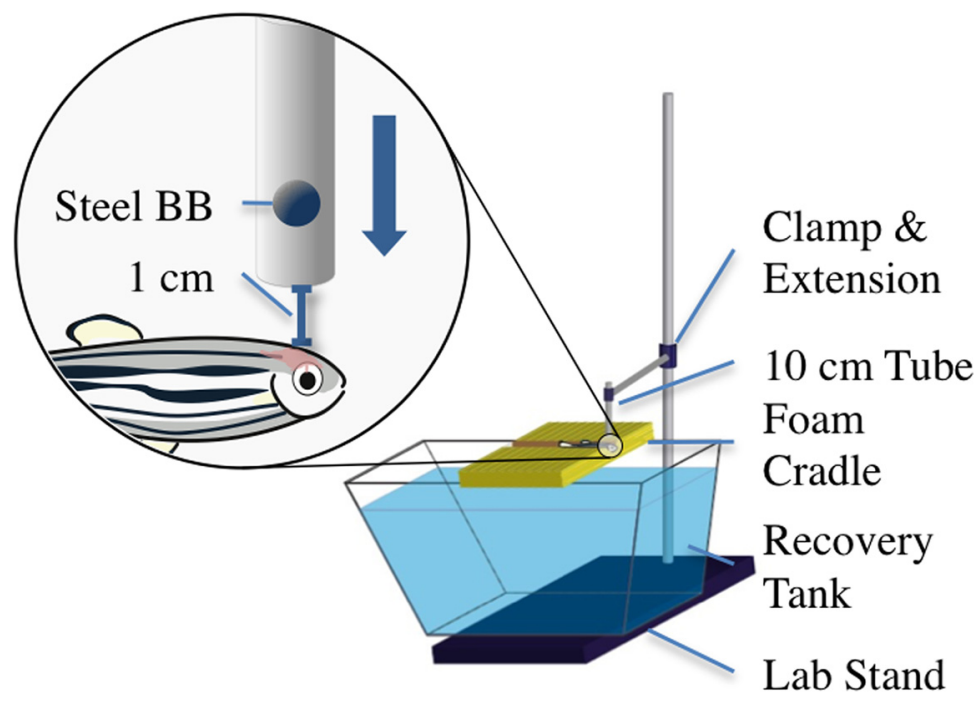

Figure 1. The mTBI weight-drop model for adult zebrafish. This novel model allows administration of a nonpenetrating, diffuse injury to the brain of an adult zebrafish. The fish are anesthetized in $0.02 \%$ tricaine-S (MS-222), placed on the foam cradle, and given a strike from a $0.33-\mathrm{g}$ ball bearing, delivering a force of $0.0032 \mathrm{~N}$ and an impact energy of $35 \mathrm{~mJ}$. The bottom of the guide tube is fixed $\sim 1$ $\mathrm{cm}$ above the zebrafish cranium, ensuring impact in a targeted location between the eyes of the fish.

$28.5^{\circ} \mathrm{C}$, and all procedures were approved and conducted within the W.M. Keck Science Department Institutional Animal Care and Use Committee, approval number 16832. For the RNA-seq analysis, a total of 30 fish were used and divided into three main groups: control $(n=10), 3$ dpi $(n=10)$, and $21 \mathrm{dpi}(n=10)$. Each main group was then divided into two subgroups $(n=5)$ for pooled samples for RNA-seq analysis. We used 15 males and 15 females equally divided between each time point. The fish were evaluated at varying intervals of the recovery process at 3 and $21 \mathrm{dpi}$. At each interval, the fish were killed in accordance with recommended procedures of prolonged exposure to tricaine, so as not to cause unnecessary harm to the fish (Collymore et al., 2014).

\section{Weight drop model}

As previously mentioned, current TBI models for zebrafish administer only moderate or severe TBIs. Our novel mTBI model is a weight drop model adapted from an existing rodent mTBI model (Mychasiuk et al., 2014). The apparatus consists of a 36 -inch laboratory support stand as the base, with a three-prong adjustable clamp that holds a $10-\mathrm{cm}$ plastic tube with an outer diameter of $12.7 \mathrm{~mm}$ (0.5 inches) and an inner diameter of $4.76 \mathrm{~mm}$ (0.187 inches) from ePlastics. An Aquaneering M3 ZT280 2.8 $\mathrm{L}$ tank was filled with system water and placed on the support stand base beneath the tube. A foam block was set on top of the medium recovery tank to act as a cradle for the fish, and the tube was positioned to be $\sim 1 \mathrm{~cm}$ above the cranium of the fish. The foam, black polyethylene foam with 1.7-pound density, was cut to $15 \times 7 \times 1.9$ $\mathrm{cm}$, and then a Dremel hand-held rotary tool with a 0.75inch steel brush was used to define the tracks $11 \mathrm{~cm}$ apart from each other and $0.5 \mathrm{~cm}$ deep (Fig. 1). The groove that stabilizes the fish during the procedure was bored using the same steel brush attachment to grind the foam, form- ing a $0.75-\mathrm{cm}$ wide and $0.5-\mathrm{cm}$ deep groove across the surface of the foam.

Fish were anesthetized in $0.02 \%$ tricaine-S (MS-222) solution, made from a $5-\mathrm{mL}$ aliquot in $95 \mathrm{~mL}$ system water. With a large number of animals, two $150-\mathrm{ml}$ beakers were used to speed the process, allowing for alternating times staggered at $60 \mathrm{~s}$. Sufficient anesthesia was determined with negative motor response to a tail pinch with forceps and positive gill fluctuation. The fish were then quickly removed from the MS-222 solution and placed in the foam cradle beneath the plastic tube with its dorsal side erect, ventral side to the foam, and anterior end hanging just over the edge of the foam so that the gills were in line with the edge of the foam block. The superior side of the head was aligned below the tube by looking through the tube and ensuring a weight would strike the cranium. A single $4.5-\mathrm{mm}$ steel $\mathrm{BB}$, with a mass of $0.33 \mathrm{~g}$ and weight of $0.0032 \mathrm{~N}$, was dropped, reaching a maximum speed of $1.5 \mathrm{~m} / \mathrm{s}$ in $0.073 \mathrm{~s}$, and striking the cranium with a maximum impact energy of $35 \mathrm{~mJ}$. The fish were then quickly placed into the fish water below the foam. This process was repeated for all fish in the MTBI groups. For the control group, the fish were anesthetized with the same solution as the mTBI groups. The control fish were then placed on the foam cradle for approximately the same time the mTBI fish were placed on the foam cradle, $10 \mathrm{~s}$, then placed in the recovery tank. Once recovered, the fish were placed in tanks marked as control, $3 \mathrm{dpi}$, or $21 \mathrm{dpi}$

\section{Behavioral testing}

To test brain function via behavior between control and mTBI zebrafish, a memory and swimming test apparatus was adapted and modified from the aquatic threechamber arena used in an experiment to characterize and compare behavior indicative of spatial memory in zebrafish (Norton and Bally-Cuif, 2010; Barba-Escobedo 
Table 1. Time to shoal was found to be significantly longer in the mTBI versus control group

\begin{tabular}{llllll}
\hline Sample & Pre-injury & $0 \mathrm{dpi}$ & $1 \mathrm{dpi}$ & $2 \mathrm{dpi}$ & $3 \mathrm{dpi}$ \\
Control & $9.9 \pm 3.949$ & $13.405 \pm 5.429 *$ & $11.223 \pm 2.753 *$ & $8.535 \pm 2.534$ & $6.62 \pm 3.37 *$ \\
mTBI & $9.9 \pm 3.949$ & $107.488 \pm 63.267 *$ & $48.378 \pm 29.949 *$ & $17.82 \pm 11.197$ & $15.97 \pm 6.65 *$
\end{tabular}

Spatial memory testing was conducted $1 \mathrm{~h}$ after injury on the day of $\mathrm{mTBI}$ induction (day 0 ) as well as once per day for $3 \mathrm{~d}$ after the administration of mTB and sham injuries. Average time to shoal measured in seconds for mTBI and control zebrafish found a statically significant difference between mTBI and sham controls, although no significant effect was found between days or among the interaction effect, $p=0.034, F(1,5)=8.324$. Tukey's multiple comparison post hoc test confirmed that days 0,1 , and $3 \mathrm{dpi}$ were significantly different between groups (A). $n=6$ per group.

$*$ Significant difference between $\mathrm{mTBI}$ and control groups on that specific day by Tukey multiple comparison post hoc analysis $(p<0.05)$.

and Gould, 2012; Stewart et al., 2014). For our experimentation, this three-chambered arena took the form of a Plexiglas T-maze. The middle arm served as a runway, and the two side arms were partitioned off from the runway by a transparent Plexiglas door. Fish were acclimated to the T-maze for $8 \mathrm{~d}$ before mTBI induction. On that day (day -8), all experimental zebrafish $(n=12)$ explored for $15 \mathrm{~min}$, followed by half of the fish per session ( $n=6$ ) on day -7 , and finally individual exploration $(n=1)$ for day -6 . After acclimation to the tank, zebrafish $(n=12)$ underwent spatial memory training sessions once per day over 5 d (days -5 to -1 ). Because of the zebrafish preference for shoaling, free swimming, separately housed zebrafish $(n=5)$ were placed in the two side arms of the maze to serve as a shoaling reward at the end of the runway. In each training session, individual fish were placed at the beginning of the middle arm, or the runway, of the T-maze and allowed to swim freely until reaching the transparent Plexiglas partition at the end of the runway that separated the subject from the shoaling fish in the two side arms. This was done to train experimental zebrafish spatial memory regarding the location of the shoaling fish. Time to reach the transparent partition, or shoaling time, was videorecorded for each training session. The day after the final training, on day 0 of the experiment, the fish were randomly placed into 2 groups $(n=6)$, and 1 group received an mTBI. After a $1 \mathrm{~h}$ recovery time, time to shoal spatial memory tests were conducted on each fish in its respective group. This test was repeated daily for 3 additional dpi. In this test, all variables were identical to training except for the removal of shoaling fish from the maze. The videos were then analyzed via a blind researcher who recorded the duration in seconds of time to shoal. This behavioral test was replicated a second time $(n=6)$ to ensure validity. Repeated-measures ANOVA was used to determine significance between groups and between days and the interaction effect between both groups and days. A Tukey multiple comparisons post hoc test was then performed if significance was found from the initial repeated-measures ANOVA (Prism 6, GraphPad Software).

\section{RNA sample preparation}

After mTBI, the zebrafish $(n=10)$ had a $93.3 \%$ survival rate. The remaining fish were killed, and the brain tissue was placed in RNAlater. RNA was isolated and purified from the brain tissue samples with the RNAeasy Minikit by Qiagen according to the manufacturer's instructions. The purified RNA was pooled into two samples for each of the three groups and sequenced as unpaired, single-ended strands by GeneWiz.

\section{Differential gene expression analysis}

RNA-sequencing FASTQ files were uploaded to Galaxy (usegalaxy.org), an open-source data analysis website equipped with bioinformatic packages and tools (Afgan et al., 2016). The sequencing files were trimmed according to a quality score $\geq 20$ using the FASTQ Quality Trimmer, and the 6-nucleotide-long Illumina indices were trimmed off the 5' ends of the RNA using Trim Galore!. Using Tophat, the trimmed sequences were mapped to the Genome Reference Consortium Zebrafish Build 10 (GrCz10/DanRer10) assembly of the zebrafish genome (released September 2014). The number of reads mapped to each gene feature of the reference genome was counted with Htseq-count, and differences in counts between control and $\mathrm{mTBI}$ groups were determined with DESeq2 (Love et al., 2014), a negative binomial distribution model. Significant DEGs were identified according to a $0.05 p$-value corrected for a false discovery rate (FDR) for multiple testing. Statistical analysis was performed in Prism.

\section{Gene ontology}

The Ensembl identification (uswest.ensembl.org) for each gene was determined using the Ensembl genome browser (Yates et al., 2016). The Ensembl identifiers were input into GOrilla (cbl-gorilla.cs.technion.ac.il; a customizable web source that integrates biological datasets), which grouped the significant DEGs according to three umbrella categories of cellular function: biological processes, cellular components, and molecular function (Eden et al., 2009).

\section{Quantitative RT-PCR}

cDNA was synthesized from total RNA from three pooled fish per time point using cDNA RT Kit 4368814 (Thermo Fisher Scientific), and quantitative PCR was performed using SYBR green master mix (Life Technologies) in an ABI PRISM 7900HT (Life Technologies) instrument using the following primers: Apoeb-F, 5'-GCAGATGAC

Table 2. Alignment results of RNA sequence samples to zebrafish reference genome

\begin{tabular}{lllll}
\hline & & Filtered & & Mapping \\
Sample & Raw reads & reads & Mapped & rate (\%) \\
Control A & $25,848,096$ & $25,843,032$ & $23,655,092$ & 91.50 \\
Control B & $27,542,279$ & $27,537,682$ & $25,250,525$ & 91.70 \\
3 dpi A & $27,655,407$ & $27,650,295$ & $25,271,599$ & 91.50 \\
3 dpi B & $29,271,785$ & $29,265,732$ & $26,784,112$ & 91.40 \\
21 dpi A & $26,258,485$ & $26,253,619$ & $24,029,275$ & 91.40 \\
21 dpi B & $26,700,791$ & $26,696,129$ & $24,409,763$ & 91.50
\end{tabular}




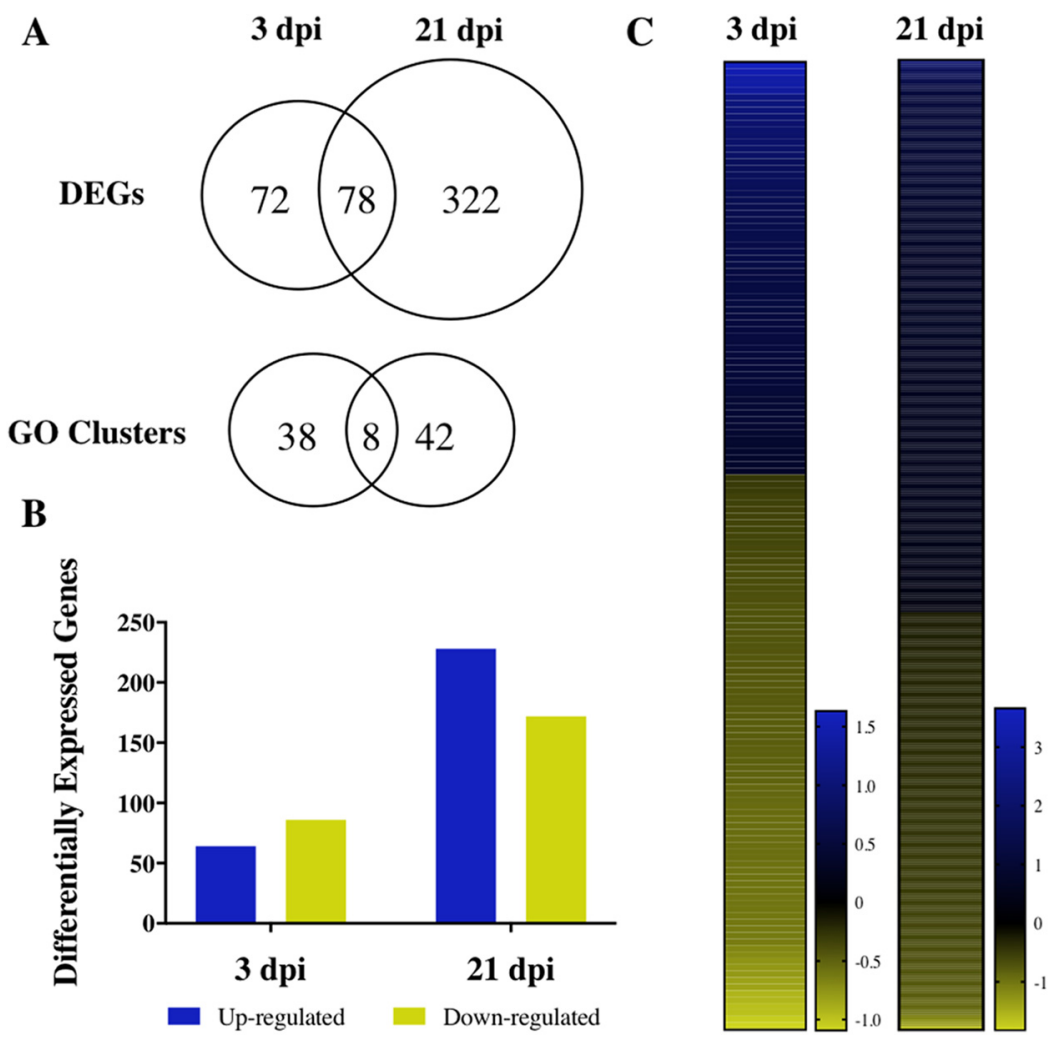

Figure 2. Summary of differential gene analysis and GO enrichment results. The number of shared and mutually exclusive DEGs (A) and GO categories between 3 and 21 dpi $(p<0.05)$. The total number of up and down-regulated genes $(\boldsymbol{B})$ and heat maps $(\boldsymbol{C})$ showing log-2 fold change of gene expression in comparison to the control group.

GTGAAGAACCG-3'; Aboeb-R, 5'-GTTGCTACGGTGTTG CGGAT-3', Loxl2b-F, 5'-AAGCAGGGATTTACACTTCGGA-3', Loxl2b-R, 5'-AGCCAGCATAATGACAGAGGC-3', Notch1b-F, 5'-GTAGATGCAGCGATGGTGTTG-3', Notch1b-R, 5'-AGC CGTCTCGTAACTTCCTTC-3'. $\Delta$ Ct was calculated using Elongation factor $1-\alpha(E F 1 \alpha)$ as a reference gene, using the following primers: EF1a-F, 5'-CAGCTGATCGTTGGA GTCAA-3', and EF1a-R, 5'-TGTATGCGCTGACTTCC TTG-3' ${ }^{\prime}$. Relative expression levels were determined using the $\Delta \Delta$ Ct method (Livak and Schmittgen, 2001), normalized to age-matched controls that did not receive mild traumatic brain injury.

\section{Results}

\section{Mild traumatic brain injury model}

Modification of an existing rodent weight drop model was necessary to create a suitable fish model for mTBI (Fig. 1; Mychasiuk et al., 2014). The mTBI weight drop model for adult zebrafish establishes a protocol for con- sistent application of a head injury that represents a blow or a strike. Observations are that the procedure leaves little epidermal damage, with a minor number of cases presenting a small indentation from the ball bearing at the strike location. This procedure is modestly rapid from the time the fish is placed in the anesthesia, until the time it is placed in the recovery tank.

\section{Behavioral analysis}

To validate our mTBI model, we performed a spatial memory behavioral test. This test measured the time it took fish to remember the location of a school of fish they had previously swam with. Previous studies have shown that zebrafish prefer swimming in groups, also known as shoaling, to avoid predation and improve foraging in the wild (Miller and Gerlai, 2012). This test specifically measured the animal's spatial memory with regard to time to shoal (Barba-Escobedo and Gould, 2012; Miller and Gerlai, 2012; Stewart et al., 2014). Results from this test

Table 3. Representative sample of GO categories associated with DEGs at $3 \mathrm{dpi}$

\begin{tabular}{lllr}
\hline Category & GO ID & Description & $p$-value \\
Biological process & GO:0051591 & Response to cAMP & $1.09 \times 10^{5}$ \\
Biological process & GO:0006470 & Protein dephosphorylation & $3.85 \times 10^{5}$ \\
Biological process & GO:0048519 & Negative regulation of biological process & $5.77 \times 10^{4}$ \\
Biological process & GO:0010941 & Regulation of cell death & $8.35 \times 10^{4}$ \\
Molecular function & GO:0017017 & MAP kinase tyrosine/serine/threonine phosphatase activity & $1.86 \times 10^{5}$ \\
Molecular function & GO:0005184 & Neuropeptide hormone activity & $4.60 \times 10^{4}$
\end{tabular}


A

\section{Regulation of Cell Death}

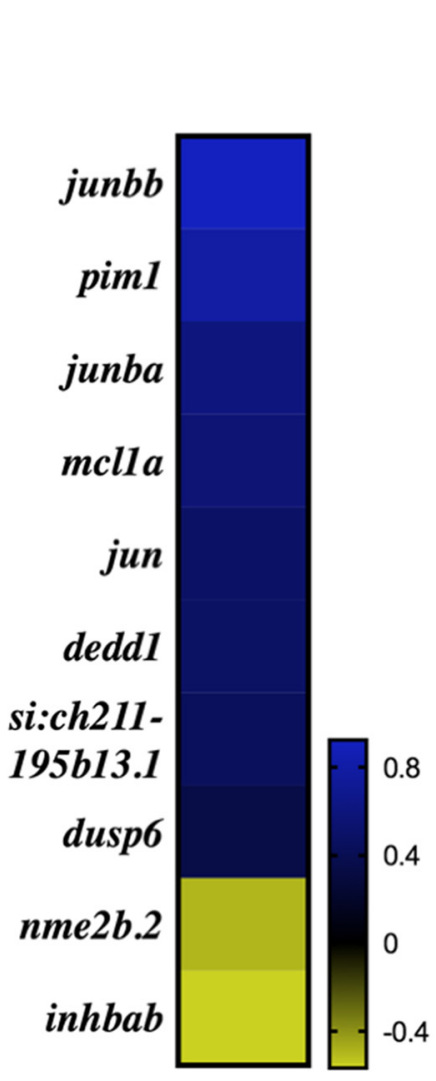

B

\section{Negative Regulation of Biological Processes}

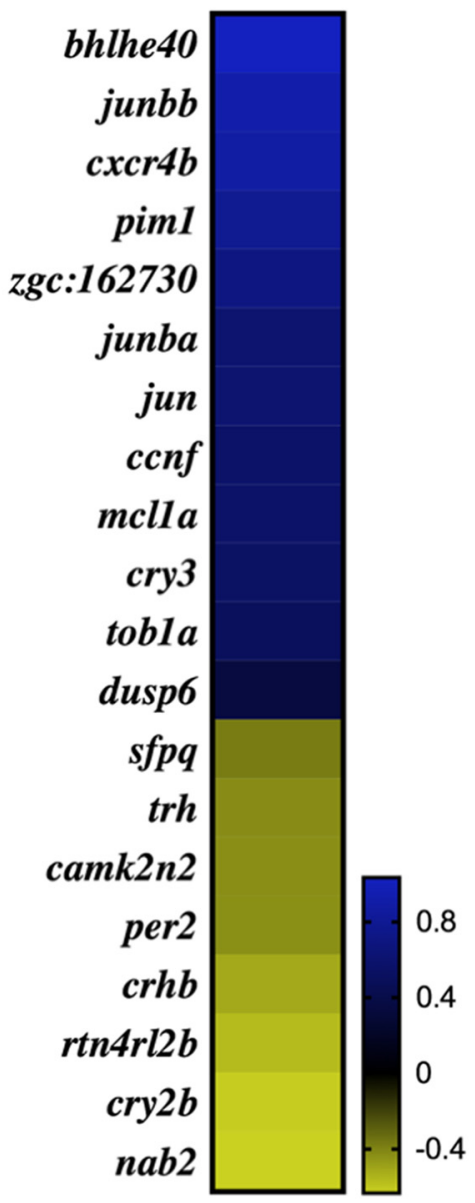

Figure 3. GO categories encompassing early response to injury at 3 dpi. Log-2 fold change of DEGs within regulation of cell death $(\boldsymbol{A})$ and negative regulation of biological processes $(\boldsymbol{B})$.

confirmed that mTBI fish took significantly longer to locate the correct spatial location of shoaling than sham controls on the day of mTBI induction as well as 1 and 3 dpi. Interestingly, the mTBI group demonstrated a clear improvement over in time to shoal over the 0-3 dpi, though this trend was not statistically significant. While the largest difference in both behavioral tests occurred between groups at day 0 , the day of $\mathrm{mTBI}$ induction, clear differences between groups were still discernable at $3 \mathrm{dpi}$ (Table 1).

\section{RNA analysis}

To assess changes in gene expression in the brain following mTBI, control, 3-dpi, and 21-dpi animals were killed and had their brains prepared for RNA-seq analysis. The RNA samples were sequenced by next-generation sequencing, which, on average, generated more than 27 million reads per sample (Table 2). Filtered and trimmed reads were then mapped to the zebrafish DanRer10 ref- erence genome with an average mapping rate of $91.5 \%$. Exon features of mapped reads from a non-strandspecific assay for 3 and 21 dpi were counted with Htseqcount in union mode and compared to control read counts using DESeq2 with a parametric fit type. The significant DEGs were identified according to an FDRcorrected $p$-value of 0.05 , resulting in 150 DEGs at 3 dpi and 400 DEGs at $21 \mathrm{dpi}$ (Fig. 2A; Tables 5, 6, and 7). At 3 dpi, $43 \%$ of DEGs were up-regulated, in comparison to $57 \%$ of DEGs at 21 dpi (Fig. 2B). The log-2 fold change range for DEGs at 21 dpi was nearly 5.5, which was twice the log-2 fold change range observed at 3 dpi (Fig. 2C).

The DEGs were then sorted according to their respective GO categories at an FDR-corrected 95\% confidence interval for a total of 46 and $50 \mathrm{GO}$ terms at 3 and $21 \mathrm{dpi}$, respectively (Fig. 2A). At $3 \mathrm{dpi}, 60 \%$ of the $\mathrm{GO}$ categories were enriched within biological processes, $40 \%$ within molecular function, and none within cellular components (Table 3). At $21 \mathrm{dpi}$, there were GO clusters associated 


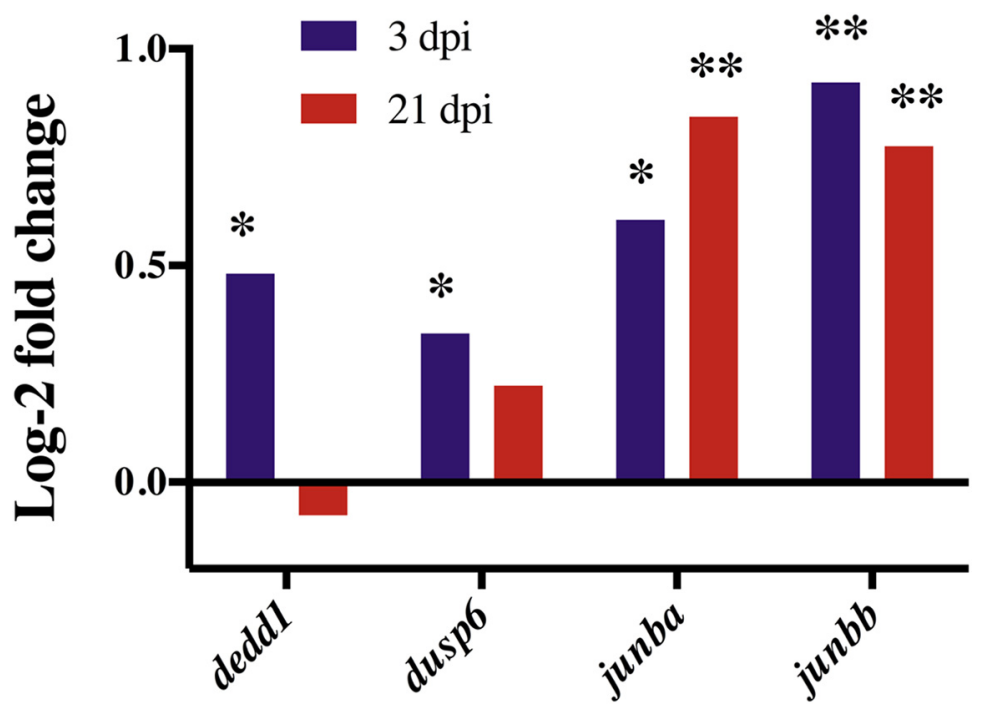

Figure 4. Expression of pro-apoptotic DEGs at 3 and $21 \mathrm{dpi}$. At $3 \mathrm{dpi}$, dedd1 ( $p=0.0207)$, dusp6 ( $p=0.0239)$, junba ( $p=0.0008$ ), and junbb $(p<0.0001)$ were significantly up-regulated. Only junba and junbb were significantly upregulated at $21 \mathrm{dpi}(p<0.0001)$. $* p<0.05 ; * * p<0.0001$.

with each category with $50 \%$ in biological processes, $20 \%$ in molecular function, and $30 \%$ in cellular components. Between 3 and $21 \mathrm{dpi}, 11 \%$ of the biological processes GO categories and $7 \%$ of the molecular function GO categories were shared. At $3 \mathrm{dpi}$, GO clusters mainly encapsulated chemical and hormonal signaling pathways, including the cyclic adenosine monophosphate (cAMP) and mitogen-activated protein (MAP) kinase pathways (Table 3). In addition, more than $30 \%$ of the GO categories related to phosphate-containing compounds, dephosphorylation, and phosphatase activity. Two notable GO clusters include regulation of cell death and negative regulation of biological processes, which exhibited an average log- 2 fold change of 0.36 across 10 genes and 0.20 across 20 genes, respectively (Fig. 3). Specific to the regulation of cell death GO category, death effector domain (dedd1) promotes apoptosis (Lee et al., 2000) and inhibits proliferation (Arai et al., 2007). The regulation of dedd1 was significant at 3 dpi $(p=0.0207$; Fig. 4), where it was up-regulated $35 \%$ more than the average regulation of DEGs comprising regulation of cell death (Fig. $3 A$ ). Between the two GO clusters, 6 DEGs were shared, including dual-specificity phosphatase 6 , dusp6, which promotes p53-mediated cell death (Piya et al., 2012), and was significantly upregulated at $3 \mathrm{dpi}(p=0.0239$, Fig. 4). Additionally, junba and junbb, two orthologs of the mammalian Junb gene found to be required for tissue regeneration in zebrafish (Ishida et al., 2010), were significantly upregulated at both 3 dpi $(p=0.0008$ and $p<0.0001)$ and $21 \mathrm{dpi}(p<0.0001$; Fig. 4).

In comparison to the enriched GO clusters at $3 \mathrm{dpi}$, which largely comprised negatively regulated pathways, GO clusters at 21 dpi were characterized by positively regulated pathways involved in neural repair, neuroregeneration, and development. Specifically, $24 \%$ of the biological processes GO categories at $21 \mathrm{dpi}$ were developmental, and $16 \%$ involved regeneration. An additional $20 \%$ of the molecular function and $27 \%$ of the cellular component GO categories involved ATP pathways (Table 4). Four GO clusters encompassing neural repair and neuroregeneration DEGs at $21 \mathrm{dpi}$ were neuroregeneration, neuron progenitor regeneration, regulation of cell motility, and positive regulation of cellular differentiation (Fig. 5). Within regeneration, nearly $79 \%$ of the DEGs were significantly up-regulated, with an average log-2 fold change of 0.57 . Required for neurogenesis in both mammals (Wang et al., 2009) and zebrafish (Kishimoto et al., 2012), notch1b was significantly up-

Table 4. Neuroregeneration GO categories of interest associated with significant DEGs at $21 \mathrm{dpi}$

\begin{tabular}{lllr}
\hline Category & GO ID & Description & $p$-value \\
Biological process & GO:0031175 & Neuron projection development & $2.56 \times 10^{6}$ \\
& GO:0031099 & Regeneration & $3.30 \times 10^{6}$ \\
& GO:0032502 & Developmental process & $\times 10^{4}$ \\
& GO:0031102 & Neuron projection regeneration & $1.57 \times 10^{4}$ \\
& GO:2000145 & Regulation of cell motility & $\times 10^{4}$ \\
& GO:0045597 & Positive regulation of cell differentiation & $4.54 \times 10^{4}$ \\
& GO:0051094 & Positive regulation of developmental process & $4.54 \times 10^{4}$ \\
& GO:0032332 & Positive regulation of chondrocyte differentiation & $8.18 \times 10^{4}$ \\
Molecular function & GO:0042626 & ATPase activity, coupled to transmembrane movement of substances & $1.83 \times 10^{4}$ \\
Cellular component & GO:0005882 & Intermediate filament & $5.81 \times 10^{4}$
\end{tabular}


Table 5. DEGs unique to $3 \mathrm{dpi}$

\begin{tabular}{|c|c|}
\hline Gene & Log2 fold change ( $p$-value) \\
\hline nupr1 & $1.05\left(6.22 \times 10^{10}\right)$ \\
\hline $\mathrm{nr} 1 \mathrm{~d} 2 \mathrm{~b}$ & $0.94\left(6.06 \times 10^{12}\right)$ \\
\hline per1b & $0.91\left(5.68 \times 10^{10}\right)$ \\
\hline cxcr4b & $0.88\left(5.90 \times 10^{6}\right)^{\prime}$ \\
\hline tagapb & $0.78\left(3.48 \times 10^{5}\right)$ \\
\hline pfkfb3 & $0.71\left(9.21 \times 10^{6}\right)$ \\
\hline p4ha1b & $0.67(0.0036)$ \\
\hline dusp2 & $0.65(0.0044)$ \\
\hline phgdh & 0.64 (0.0005) \\
\hline mknk2a & $0.62(0.0072)$ \\
\hline s1pr5a & $0.62(0.0039)$ \\
\hline zgc:194659 & $0.56(0.0296)$ \\
\hline conf & $0.56(0.0245)$ \\
\hline mcl1a & $0.56(0.0003)$ \\
\hline cry3 & $0.54(0.0136)$ \\
\hline ier5 & $0.53(0.0005)$ \\
\hline znf395b & $0.53(0.0173)$ \\
\hline ccr9a & $0.52(0.0429)$ \\
\hline elac2 & $0.51(0.0183)$ \\
\hline nfkbiab & $0.49(0.0044)$ \\
\hline tob1a & $0.49(0.0058)$ \\
\hline dedd1 & $0.48(0.0207)$ \\
\hline ctps1b & $0.45(0.0424)$ \\
\hline glipr2l & $0.45(0.0311)$ \\
\hline $\mathrm{pdcd} 4 \mathrm{a}$ & $0.44(0.0054)$ \\
\hline ak4 & $0.43(0.0373)$ \\
\hline dars & $0.39(0.0362)$ \\
\hline arhgef9b & 0.38 (0.0119) \\
\hline slc7a8a & $0.38(0.0424)$ \\
\hline dusp6 & $0.34(0.0239)$ \\
\hline ewsr1a & $-0.29(0.0424)$ \\
\hline slc25a12 & $-0.35(0.0423)$ \\
\hline cirbpa & $-0.35(0.0164)$ \\
\hline alas1 & $-0.36(0.0142)$ \\
\hline jph3 & $-0.37(0.0454)$ \\
\hline vim & $-0.40(0.0239)$ \\
\hline ptp4a2b & $-0.40(0.0025)$ \\
\hline hspa8 & $-0.40(0.0016)$ \\
\hline atf7ip & $-0.41(0.0069)$ \\
\hline impdh1b & $-0.41(0.0103)$ \\
\hline trh & $-0.43(0.0259)$ \\
\hline camk2n2 & $-0.43(0.0038)$ \\
\hline susd6 & $-0.43(0.0080)$ \\
\hline $\mathrm{npb}$ & $-0.44(0.0132)$ \\
\hline slc6a17 & $-0.45(0.0046)$ \\
\hline atad3b & $-0.45(0.0239)$ \\
\hline g3bp1 & $-0.46(0.0006)$ \\
\hline cdk5r2b & $-0.46(0.0424)$ \\
\hline cad & $-0.46(0.0044)$ \\
\hline pcdh1g31 & $-0.46(0.0424)$ \\
\hline gpt2l & $-0.47(0.0244)$ \\
\hline pcsk1 & $-0.48(0.0021)$ \\
\hline crhbp & $-0.51(0.0004)$ \\
\hline mri1 & $-0.53(0.0191)$ \\
\hline rorcb & $-0.54(0.0102)$ \\
\hline rbm12 & $-0.55(0.0041)$ \\
\hline cyp39a1 & $-0.56(0.0046)$ \\
\hline si:ch73-52e5.2 & $-0.57(0.0048)$ \\
\hline dnajc9 & $-0.57(0.0016)$ \\
\hline rtn4rl2b & $-0.57(0.0102)$ \\
\hline plxnb2b & $-0.59(0.0004)$ \\
\hline \multirow[t]{2}{*}{ pdxkb } & $-0.60(0.0073)$ \\
\hline & \\
\hline
\end{tabular}

Table 5. Continued

\begin{tabular}{ll}
\hline Gene & Log2 fold change (p-value) \\
hspa4a & $-0.62\left(5.90 \times 10^{6}\right)$ \\
cry2b & $-0.63\left(4.44 \times 10^{8}\right)$ \\
nab2 & $-0.63(0.0054)$ \\
clocka & $-0.64(0.0017)$ \\
hmox1a & $-0.70(0.0018)$ \\
LOC564685 & $-0.72(0.0004)$ \\
ppm1e & $-0.78\left(7.94 \times 10^{8}\right)$ \\
pde10a & $-0.79\left(3.69 \times 10^{6}\right)$ \\
arnt12 & $-0.93\left(1.45 \times 10^{6}\right)$ \\
nr1d4b & $-1.05\left(7.88 \times 10^{9}\right)$ \\
\hline
\end{tabular}

regulated at 3 dpi $(p=0.026)$ and 21 dpi $(p<0.0001$, Fig. $6 A)$. In contrast to the regeneration GO cluster, only $30 \%$ of the DEGs within neuron progenitor regeneration were up-regulated (Fig. 5B). Categorized into both the regeneration and neuron progenitor regeneration GO clusters, a gene involved in amyloid beta clearance, apoeb (Castellano et al., 2011), was significantly up-regulated at 21 dpi $(p<0.0001$; Fig. $6 A, B)$

Radial glial cells (RGCs), which function as neuronal progenitor cells (NPCs), and facilitate neuronal transport, are significant to zebrafish neuroregeneration and neural repair (Kishimoto et al., 2012; Than-Trong and Bally-Cuif, 2015). In contrast to humans, zebrafish neuroregeneration is not inhibited by the formation of a glial scar due, in part, to the gene, ctgfa, which stimulates glial bridging (Mokalled et al., 2016). Categorized in the developmental process GO category, ctgfa was significantly up-regulated at $21 \mathrm{dpi}(p<$ 0.0001; Fig. 6A). RGC marker cxcl12a was also significantly up-regulated at $21 \mathrm{dpi}(p=0.0095$; Fig. $6 A)$. In addition to regeneration, $c x c / 12 a$ was categorized into regulation of cell motility and positive regulation of cellular differentiation GO clusters, wherein $100 \%$ and $91 \%$ of DEGs were up-regulated, respectively (Fig. 5). Within positive regulation of cellular differentiation, lysyl oxidase-like 2 genes, Iox/2a and $/ 0 x / 2 b$, were also upregulated at 21 dpi $(p<0.0001$; Fig. $6 A, B)$. The lox/2 genes are significant for neuronal repair, as loss of the lox/2 genes has been shown to impair neural differentiation (Iturbide et al., 2015). Of the DEGs involved in neuroregeneration, half were selected for qPCR validation (Fig. 6B). Both RNAseq and GPCR analysis revealed a similar increase in the upregulation of apoeb, lox/2b, and notch $1 b$ from 3 to 21 dpi.

\section{Discussion}

With the high prevalence of mTBls characterized by both short- and long-term cognitive effects, it is critical to develop an efficient, yet inexpensive, mTBI model that can be replicated in any laboratory. With DEGs categorized into GO clusters indicative of a peak injury response at $3 \mathrm{dpi}$ and a peak neuroregeneration response at $21 \mathrm{dpi}$, this study validates a novel adult zebrafish mTBI model that requires minimal equipment in addition to a standard zebrafish aquatic housing system. In the efficient and effective setup, only a standardized ball bearing, clamped tube apparatus, and foam block cradle are required to adequately administer consistent mTBIs. This flexible model 
Table 6. Continued

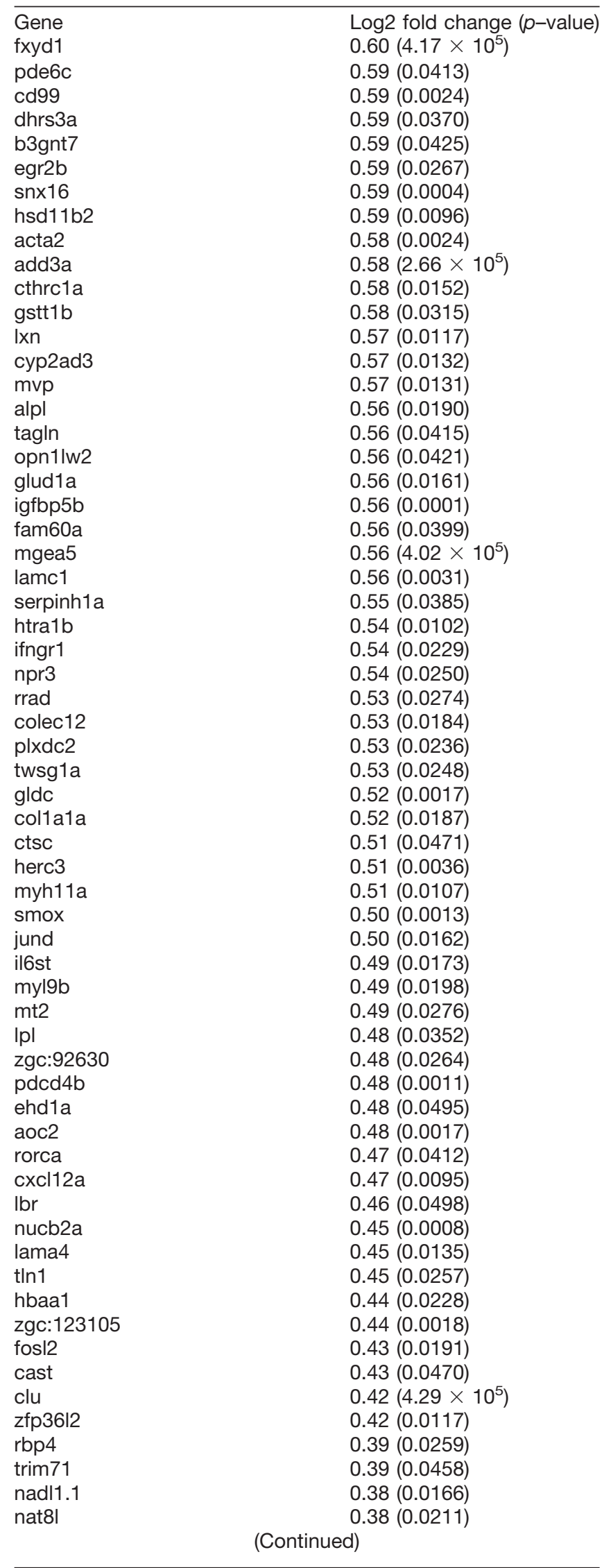

Table 6. Continued

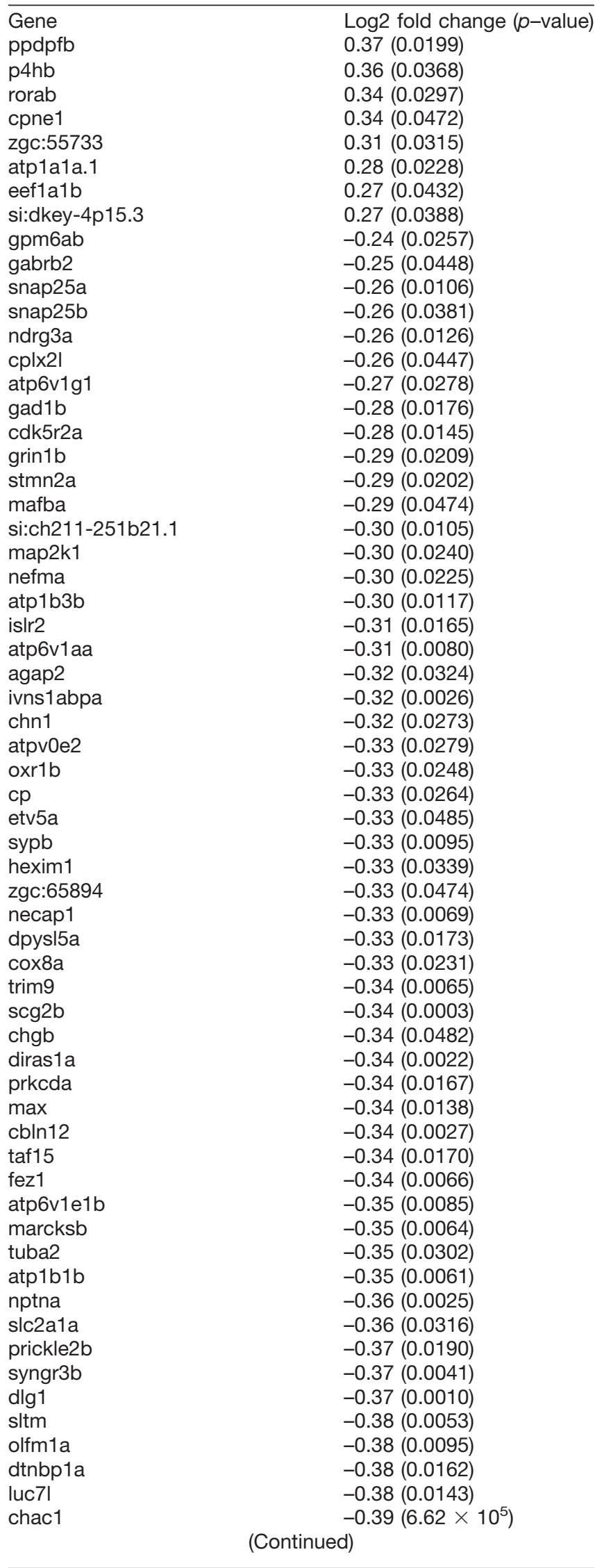


Table 6. Continued

\begin{tabular}{|c|c|}
\hline Gene & Log2 fold change ( $p$-value) \\
\hline kctd12.2 & $-0.39(0.0125)$ \\
\hline adcy8 & $-0.39(0.0216)$ \\
\hline b3gat2 & $-0.39(0.0135)$ \\
\hline sub1b & $-0.39(0.0235)$ \\
\hline h2afvb & $-0.39(0.0250)$ \\
\hline zgc:101840 & $-0.39(0.0293)$ \\
\hline stxbp6I & $-0.40(0.0008)$ \\
\hline syt12 & $-0.41(0.0010)$ \\
\hline ifrd1 & $-0.41(0.0084)$ \\
\hline sst3 & $-0.41(0.0078)$ \\
\hline si:ch211-203b8.6 & $-0.42(0.0009)$ \\
\hline gnb5b & $-0.42(0.0285)$ \\
\hline smyd2a & $-0.42(0.0014)$ \\
\hline txndc12 & $-0.42(0.0320)$ \\
\hline cd9b & $-0.43(0.0093)$ \\
\hline tubb2b & $-0.43(0.0150)$ \\
\hline atp1b3a & $-0.44(0.0044)$ \\
\hline ccdc85al & $-0.45(0.0095)$ \\
\hline tiparp & $-0.45(0.0308)$ \\
\hline hsbp1a & $-0.45(0.0402)$ \\
\hline sumo2b & $-0.45(0.0028)$ \\
\hline sult2st3 & $-0.45(0.0081)$ \\
\hline zwi & $-0.46(0.0150)$ \\
\hline abcc5 & $-0.46(0.0066)$ \\
\hline stk25a & $-0.46(0.0344)$ \\
\hline ucn3l & $-0.46(0.0171)$ \\
\hline Imo2 & $-0.46(0.0486)$ \\
\hline oaz1b & $-0.47\left(1.41 \times 10^{5}\right)$ \\
\hline phkg1a & $-0.48(0.0487)$ \\
\hline nefmb & $-0.49(0.0071)$ \\
\hline sox7 & $-0.49(0.0349)$ \\
\hline gng13b & $-0.49\left(6.36 \times 10^{5}\right)$ \\
\hline nrn1a & $-0.49(0.0037)$ \\
\hline csrp1b & $-0.50(0.0036)$ \\
\hline tmbim4 & $-0.50(0.0001)$ \\
\hline snapc5 & $-0.50(0.0010)$ \\
\hline zgc:77056 & $-0.51(0.0228)$ \\
\hline hmgb3a & $-0.52\left(8.89 \times 10^{6}\right)$ \\
\hline pkn1b & $-0.53\left(7.33 \times 10^{5}\right)$ \\
\hline plp1a & $-0.53(0.0245)$ \\
\hline pltp & $-0.53(0.0055)$ \\
\hline zgc:73226 & $-0.55(0.0206)$ \\
\hline mid1ip1b & $-0.55(0.0018)$ \\
\hline rbmx & $-0.56\left(6.82 \times 10^{7}\right)$ \\
\hline gapdh & $-0.57(0.0493)$ \\
\hline si:dkey-222p3.1 & $-0.57(0.0419)$ \\
\hline siglec15I & $-0.59(0.0399)$ \\
\hline cx27.5 & $-0.59(0.0007)$ \\
\hline oxt & $-0.59(0.0014)$ \\
\hline slc25a22 & $-0.61(0.0031)$ \\
\hline iqch & $-0.61(0.0165)$ \\
\hline tnnc2 & $-0.61(0.0248)$ \\
\hline cldnk & $-0.62\left(2.63 \times 10^{6}\right)$ \\
\hline rnf144ab & $-0.62(0.0001)$ \\
\hline erf & $-0.66(0.0017)$ \\
\hline flj13639 & $-0.66\left(1.47 \times 10^{7}\right)$ \\
\hline $\mathrm{mpz}$ & $-0.68\left(9.11 \times 10^{9}\right)$ \\
\hline lancl1 & $-0.69\left(1.92 \times 10^{8}\right)$ \\
\hline pvalb3 & $-0.70(0.0007)$ \\
\hline sult2st1 & $-0.71(0.0062)$ \\
\hline si:ch211-147k10.6 & $-0.71\left(6.34 \times 10^{5}\right)$ \\
\hline & d) \\
\hline
\end{tabular}

Table 6. Continued

\begin{tabular}{ll}
\hline Gene & Log2 fold change $(p-$ value $)$ \\
foxh1 & $-0.73(0.0023)$ \\
apoa1b & $-0.76(0.0026)$ \\
tfap2c & $-0.76(0.0017)$ \\
olfm2b & $-0.77\left(4.58 \times 10^{11}\right)$ \\
mstna & $-0.79(0.0014)$ \\
asb15b & $-0.80(0.0010)$ \\
plp1b & $-0.80\left(9.36 \times 10^{9}\right)$ \\
tnnt3b & $-0.87(0.0001)$ \\
pth2 & $-0.87\left(9.47 \times 10^{6}\right)$ \\
myhc4 & $-0.95\left(4.35 \times 10^{6}\right)$ \\
mylpfa & $-1.09\left(5.90 \times 10^{7}\right)$ \\
atp2a11 & $-1.16\left(1.92 \times 10^{8}\right)$ \\
pvalb4 & $-1.25\left(1.02 \times 10^{9}\right)$ \\
gpx1a & $-1.31\left(5.71 \times 10^{18}\right)$ \\
\hline
\end{tabular}

can also be adapted to observe the effects of differing traumatic brain injuries such as multiple, less severe impacts characteristic of chronic traumatic encephalopathy (Mouzon et al., 2014; Petraglia et al., 2014). Additionally, this novel model also has a behavioral assay that can measure spatial memory deficits in $\mathrm{mTBI}$ fish, an effect observed in other mTBI animal models and human patients (Lu et al., 2005; Lundin et al., 2006; Chen et al., 2012; Dawish et al., 2012; Luo et al., 2017).

Zebrafish make an excellent disease model because zebrafish and human brains share a high degree of homology, with $70 \%$ of human genes having at least one obvious zebrafish orthologue (Howe et al., 2013). The development of this mTBI model is especially significant, as it utilizes zebrafish, which share a strikingly similar genome to humans. This genomic similarity has important implications for the application of zebrafish neuroregeneration to the human brain. Additionally, the remarkable similarity, especially in the disease genome, between humans and zebrafish provides scientists with substantial research potential and promising pharmaceutical benefits (Lieschke and Currie, 2007). In accordance with the timelines observed in previous studies (Kishimoto et al., 2012; Kyritsis et al., 2012) as well as our previous data (not shown), GO categories in cell death and injury were expected at $3 \mathrm{dpi}$, while neuroregeneration and neural repair were expected at $21 \mathrm{dpi}$ according to the novel zebrafish mTBI model. Specifically, response to cAMP was a significant GO cluster at $3 \mathrm{dpi}$ (Table 3), which has been shown to promote neuronal survival (Hansen et al., 2003). Furthermore, up-regulation of the CAMP cascade has been shown to increase cellular proliferation (Nakagawa et al., 2002) and the number of new neurons (Zhu et al., 2004). MAP kinase tyrosine/serine/threonine phosphatase activity was also a GO category of interest at $3 \mathrm{dpi}$. Significantly, the MAP signaling pathway has been shown to induce neuritic outgrowth (Creedon et al., 1996) and is required for neuronal differentiation (Samuels et al., 2008). Within the MAP-kinase family are Jun $\mathrm{N}$-terminal kinases (JNKs) that, in addition to differentiation, regulate cell proliferation and apoptosis (Dhanasekaran and Reddy, 2008) and have been identified as necessary for zebrafish tissue regeneration (Ishida et al., 2010). After the wound 
Table 7. DEGs shared between both 3 and $21 \mathrm{dpi}$

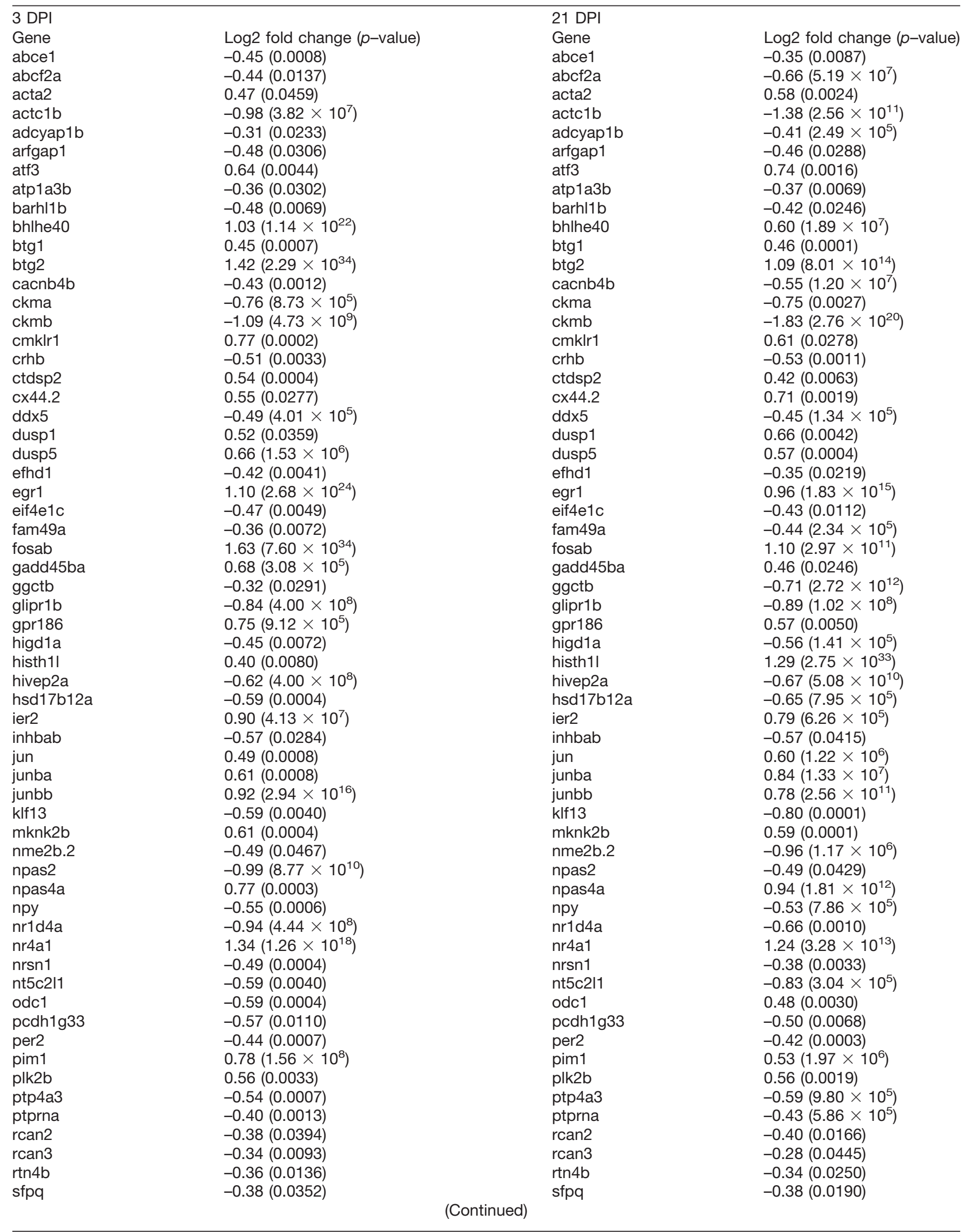


Table 7. DEGs shared between both 3 and $21 \mathrm{dpi}$

\begin{tabular}{llll}
\hline sgsm3 & $-0.34(0.0454)$ & sgsm3 & $-0.34(0.0188)$ \\
si:ch211-105j21.7 & $0.91\left(5.37 \times 10^{6}\right)$ & si:ch211-105j21.7 & $0.63(0.0231)$ \\
si:ch211-195b13.1 & $0.44(0.0472)$ & si:ch211-195b13.1 & $0.42(0.0039)$ \\
si:ch211-23714.6 & $-0.51(0.0135)$ & si:ch211-23714.6 & $-0.49(0.0188)$ \\
si:dkey-238o13.4 & $-0.83\left(2.18 \times 10^{10}\right)$ & si:dkey-238o13.4 & $-0.85\left(1.95 \times 10^{13}\right)$ \\
sik1 & $0.96\left(4.85 \times 10^{11}\right)$ & sik1 & $0.94\left(2.31 \times 10^{9}\right)$ \\
slc4a2b & $0.54(0.0351)$ & slc4a2b & $1.65\left(1.71 \times 10^{21}\right)$ \\
spred3 & $-0.50(0.0002)$ & spred3 & $-0.50\left(2.87 \times 10^{5}\right)$ \\
srsf5b & $0.40(0.0236)$ & srsf5b & $0.53\left(1.69 \times 10^{5}\right)$ \\
sst1.1 & $-0.60(0.0001)$ & sst1.1 & $-0.55(0.0011)$ \\
syt13 & $-0.60(0.0002)$ & syt13 & $-0.62\left(4.22 \times 10^{6}\right)$ \\
tmem198b & $-0.56\left(4.20 \times 10^{5}\right)$ & tmem198b & $-0.73\left(7.90 \times 10^{9}\right)$ \\
txnipa & $0.42(0.0015)$ & txnipa & $0.77\left(7.54 \times 10^{11}\right)$ \\
zgc:110340 & $0.57(0.0021)$ & zgc:110340 & $0.33(0.0196)$ \\
zgc:122979 & $1.51\left(2.03 \times 10^{29}\right)$ & zgc:122979 & $0.95\left(4.57 \times 10^{17}\right)$ \\
zgc:162730 & $0.70\left(2.39 \times 10^{5}\right)$ & zgc:162730 & $0.68(0.0036)$ \\
zgc:175128 & $1.41\left(9.66 \times 10^{25}\right)$ & zgc:175128 & $1.06\left(6.48 \times 10^{10}\right)$
\end{tabular}

healing stage, JNKs help induce regeneration by phosphorylating Junb proteins (Ishida et al., 2010), the transcripts of which were found to be significantly upregulated at both 3 and $21 \mathrm{dpi}$ (Fig. 4A). As evidenced by the enriched regulation of cell death GO category at 3 dpi (Fig. $3 A$ ), a primary response following $\mathrm{mTBls}$ is apoptosis (Kroehne et al., 2011). To promote apoptosis, JNKs can also phosphorylate p53 proteins (Oleinik et al., 2007). Overexpression of p53 transactivates dusp6, which was significantly upregulated at $3 \mathrm{dpi}$ (Fig. 4A), and induces cell death through inactivation of extracellular signal-regulated kinase 1/2 (ERK1/2; Piya et al., 2012). Apoptosis is also regulated by dedd1, a gene significantly upregulated at 3 dpi (Fig. 4A), which induces intermediate filament degradation (Lee et al., 2002).

Intermediate filaments are significant for maintaining cellular structure and facilitating transport and represent a significant GO cluster at $21 \mathrm{dpi}$ (Table 4). Damaged intermediate filaments and other cellular structures are cleared by microglia or macrophages of the CNS. Markers for apoeb, for example, have been observed in microglia (Veth et al., 2011). Significantly, apoeb was upregulated at $21 \mathrm{dpi}$ (Fig. $6 A, B$ ) and has been found to be involved in the wound healing process in both heart (Lien et al., 2006) and fin regeneration (Monnot et al., 1999; Poss et al., 2000). For regeneration, cellular differentiation is required to form new neurons that can ultimately be integrated into the site of injury. Within the positive regulation of cellular differentiation GO category enriched at $21 \mathrm{dpi}$, transcripts of the extracellular matrix proteins $10 x / 2 a$ and $l o x / 2 b$ were significantly upregulated (Fig. 6A,B). Expressed by NPCs (Maisel et al., 2007), the lox/2 genes regulate pluripotency of embryonic stem cells (ESCs), and facilitate proper neural differentiation (Iturbide et al., 2015). The lox/2 genes may also interact with the Notch 1 signaling pathway (Martin et al., 2015), which was significantly upregulated at 3 and $21 \mathrm{dpi}$ as indicated by the Notch $1 \mathrm{~b}$ transcript expression. In proliferating cells of the ventricular zone (VZ), Notch 1 signaling has been shown to promote production of NPCs that can migrate toward the site of injury (Wang et al., 2009; Kishimoto et al., 2012). Migration is critical for regeneration, as indicated by the enriched regulation of cell motility GO category at $21 \mathrm{dpi}$ (Fig. $5 \mathrm{C}$ ). In response to cortical injury, Notch signaling has been observed in conjunction with an astrogliogenic response (Givogri et al., 2006). In mammals, astrogliosis results in the formation of an inhibitory glial scar not observed in zebrafish. Instead, ctgfa, which was significantly upregulated at $21 \mathrm{dpi}$ (Fig. $6 A$ ), has been shown to induce glial bridging (Mokalled et al., 2016) where neuronal transport to the site of injury is ultimately facilitated by the filamentous RGCs. RGC marker $c x c / 12 a$, for example, was significantly upregulated at 21 dpi (Fig. 6A). With migration complete, new neurons can integrate and become fully functioning, mature neurons as indicated by the enriched neuroregeneration and neuron progenitor regeneration GO clusters at 21 dpi (Fig. 5).

Previous $\mathrm{TBI}$ studies in adult rodents have found changes in gene expression similar to those observed in this study. At $3 \mathrm{dpi}$, molecular activity within the MAP signaling pathway was significant (Table 3). Similarly, the MAP kinase cascade was found to be activated after injury in an adult rat weight-drop TBI model (Lu et al., 2015). Furthermore, postinjury quantification of newborn neurons in the hippocampus revealed increased neurogenesis after activation of the MAP signaling pathway (Lu et al., 2015). Within the MAP kinase family are JNKs that phosphorylate Junb proteins, which were upregulated at both 3 and $21 \mathrm{dpi}$ (Fig. 4A). Increased Junb ipsilateral to the site of injury was also found after injury in a mild fluid percussion TBI model in rats (Raghupathi and Mclntosh, 1996; Abrous et al., 1999).

At $21 \mathrm{dpi}$, genes specific to regeneration were differentially expressed, as observed in previous TBI studies. For example, the zebrafish transcript, apoeb, was significantly upregulated at $21 \mathrm{dpi}$ (Fig. 6A,B). Likewise, in an adult rat study of parasagittal fluid percussion brain injury, an increase in ApoE mRNA expression was found around the cortical lesion site (Iwata et al., 2005). At both 3 and 21 dpi, Notch1b, involved in the Notch signaling pathway, was significantly upregulated (Fig. $6 A, B$ ). Similarly, a cortical stab wound injury model in mice found the Notch signaling pathway to be activated after injury (Givogri et al., 2006). More recently, postinjury upregulation of 
A
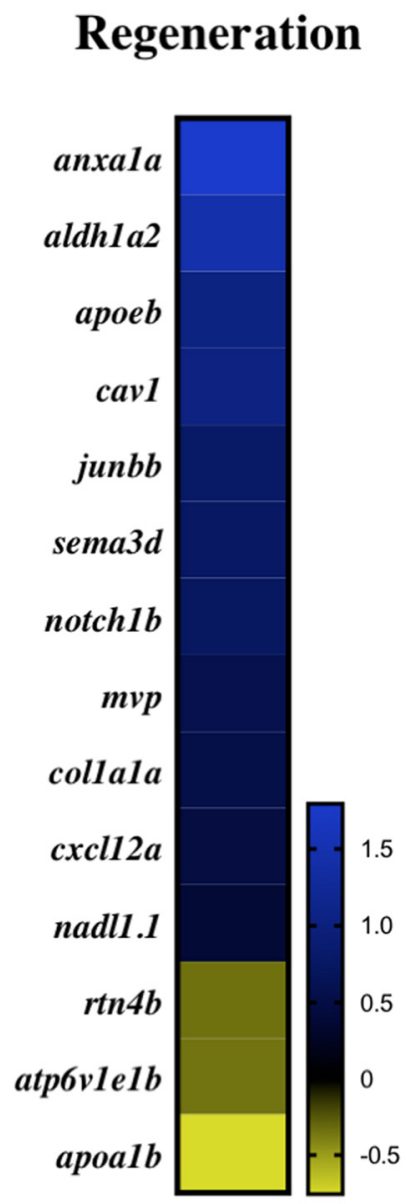

C

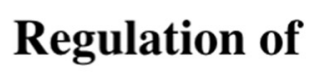
Cell Motility

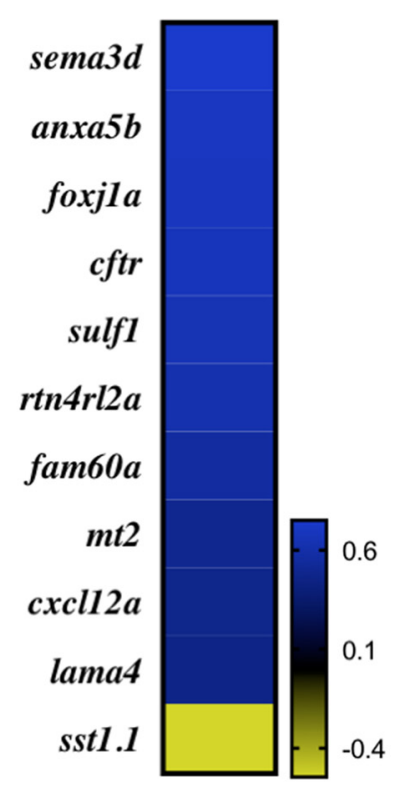

B Neuron Progenitor Regeneration

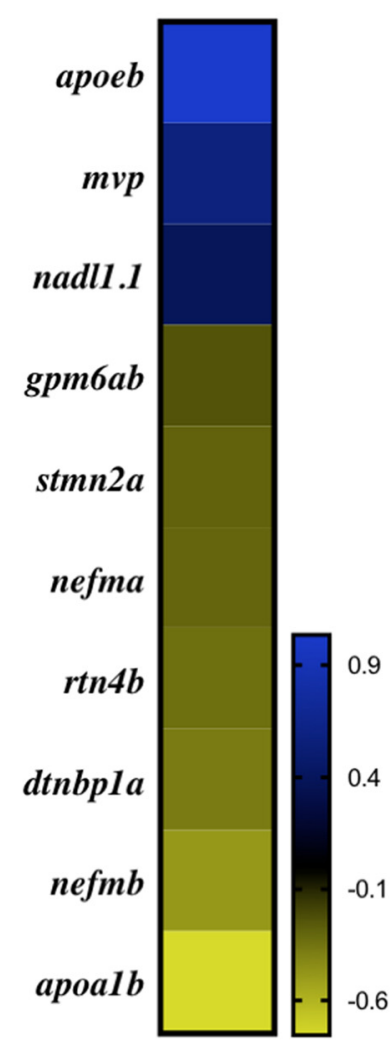

D

Positive Regulation of Cellular Differentiation

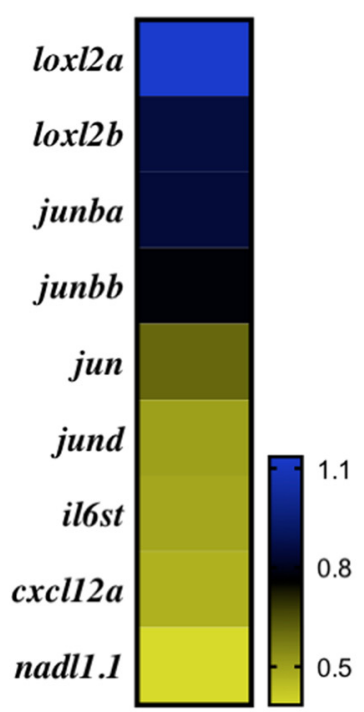

Figure 5. Regeneration GO categories at 21 dpi. Log-2 fold change of DEGs within regeneration $(\boldsymbol{A})$, neuron progenitor regeneration $(\boldsymbol{B})$, regulation of cell motility $(\boldsymbol{C})$, and positive regulation of cellular differentiation $(\boldsymbol{D})$. 

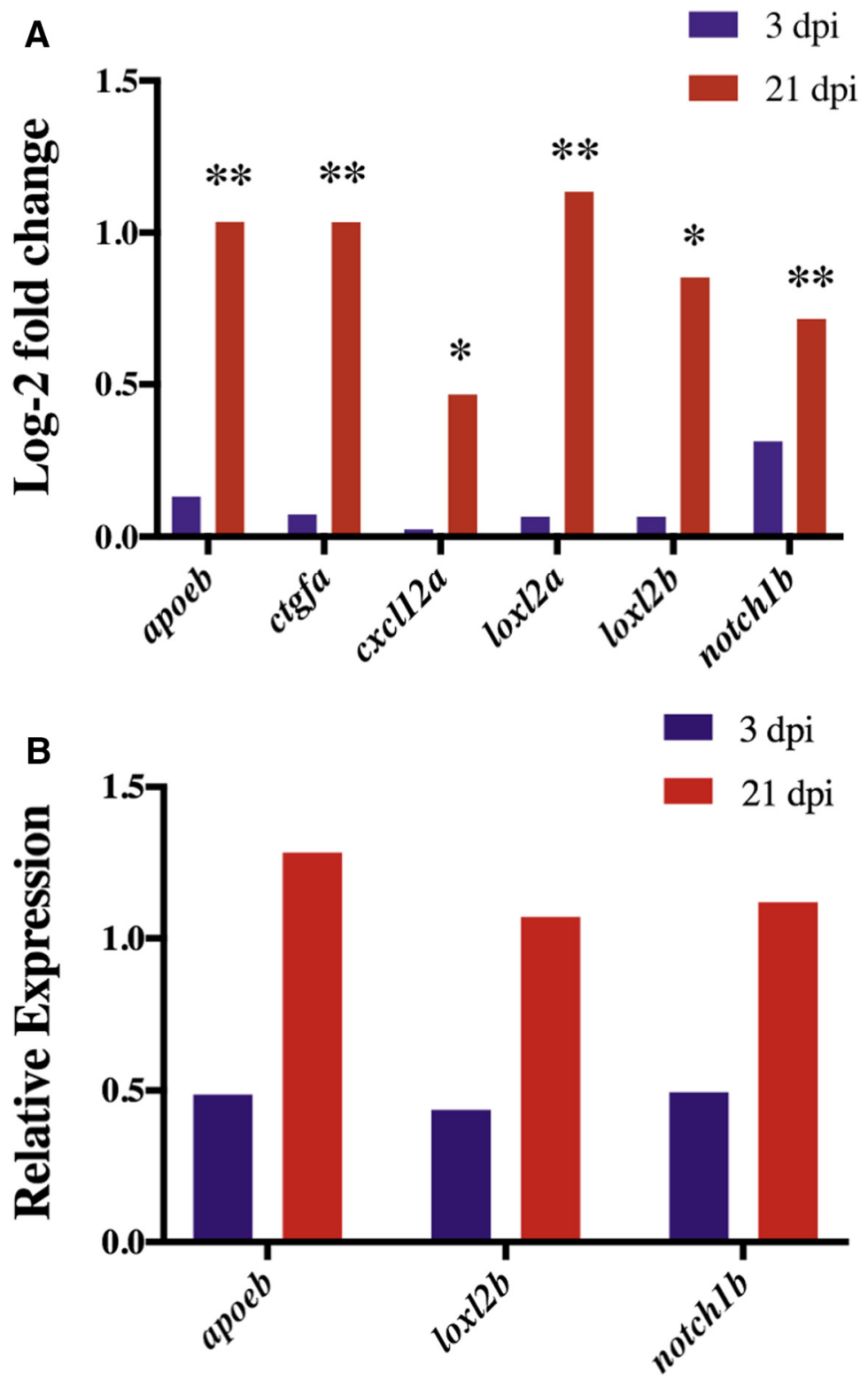

Figure 6. Expression of DEGs within neuroregeneration GO categories at 3 and $21 \mathrm{dpi}$. At $21 \mathrm{dpi}, c x c / 12 a(p=0.0095)$ and $/ 0 x / 2 b$ $(p=0.0004)$ were significantly upregulated $(\boldsymbol{A})$. The neuroregeneration DEGs apoeb, ctgfa, loxl2a, and notch $1 \mathrm{~b}$ were also significantly upregulated at $21 \mathrm{dpi}(p<0.0001) ; \boldsymbol{A}) . * p<0.05 ; * * p<0.0001$. qPCR shows that apoeb, lox/2b, and notch $1 b$ were downregulated at 3dpi but expression increased at $21 \mathrm{dpi}(\boldsymbol{B})$.

Notch1 mRNA was also observed in a lateral fluid percussion injury model in rats (Puhakka et al., 2017). The glial bridge stimulating zebrafish transcript, ctgfa, which was significantly upregulated at $21 \mathrm{dpi}($ Fig. 6A), was also the focus of a weight-drop TBI model in rats. In the rat TBI study, a significant increase in non-neuron $\mathrm{CTGF}^{+}$cells was observed at and around the lesion site over time (Liu et al., 2014).

The results of this study are two-fold: (1) the establishment and validation of a novel adult zebrafish mTBI model, and (2) the identification of significant genes and pathways involved in zebrafish CNS injury and neuroregeneration. The introduction of this effective, yet inexpensive, zebrafish $\mathrm{mTBI}$ model will significantly benefit the neuroscience community by providing greater access to study of zebrafish response to injury. In the future, additional sequencing depth may provide sufficient statistical power to identify additional differentially regulated genes involved in the response to mTBI. This same model may be used to look at additional time points, either to analyze the immediate changes in gene expression closely following injury or to longitudinally follow the neurorecovery process further. Ultimately, understanding the genetic basis of zebrafish neuroregeneration will help elucidate therapeutic targets for neural repair in humans.

\section{References}

Abrous DN, Rodriguez J, le Moal M, Moser PC, Barnéoud P (1999) Effects of mild traumatic brain injury on immunoreactivity for the inducible transcription factors C-Fos, C-Jun, JunB, and Krox-24 in 
cerebral regions associated with conditioned fear responding. Brain Res 826:181-192. May Medline

Afgan E, Baker D, van den Beek M, Blankenberg D, Bouvier D, Čech M, et al. (2016) The Galaxy platform for accessible, reproducible and collaborative biomedical analyses: 2016 update. Nucleic Acids Res 44:W3-W10. Jul 8 Medline

Arai S, Miyake K, Voit R, Nemoto S, Wakeland EK, Grummt I, et al. (2007) Death-effector domain-containing protein DEDD is an inhibitor of mitotic Cdk1/cyclin B1. Proc Natl Acad Sci U S A 104:22892294. Feb 13 Medline

Barba-Escobedo PA, Gould GG (2012) Visual social preferences of lone zebrafish in a novel environment: strain and anxiolytic effects. Genes Brain Behav 11:366-373. Apr Medline

Boyle E, Cancelliere C, Hartvigsen J, Carroll LJ, Holm LW, Cassidy JD (2014) Systematic review of prognosis after mild traumatic brain injury in the military: results of the International Collaboration on Mild Traumatic Brain Injury Prognosis. Arch Phys Med Rehabil 95:S230-S237. Mar CrossRef Medline

Castellano JM, Kim J, Stewart FR, Jiang H, DeMattos RB, Patterson $B W$, et al. (2011) Human apoE isoforms differentially regulate brain amyloid- $\beta$ peptide clearance. Sci Translat Med 3:89ra57-89ra57. Jun 29 Medline

Chen C-J, Wu C-H, Liao Y-P, Hsu H-L, Tseng Y-C, Liu H-L, et al. (2012) Working memory in patients with mild traumatic brain injury: functional MR imaging analysis. Radiology 264:844-851. Sep CrossRef Medline

Collymore C, Tolwani A, Lieggi C, Rasmussen S (2014) Efficacy and safety of 5 anesthetics in adult zebrafish (Danio rerio). J Am Assoc Lab Anim Sci 53:198-203. Mar Medline

Corrigan JD, Selassie AW, Orman JAL (2010) The epidemiology of traumatic brain injury. J Head Trauma Rehabil 25:72-80. Mar CrossRef Medline

Creedon DJ, Johnson EM, Lawrence JC (1996) Mitogen-activated protein kinase-independent pathways mediate the effects of nerve growth factor and CAMP on neuronal survival. J Biol Chem 271: 20713-20718. Aug 23 CrossRef

Dawish H, Mahmood A, Schallert T, Chopp M, Therrien B (2012) Mild traumatic brain injury (MTBI) leads to spatial learning deficits. Brain Injury 26:151-165. Feb 23 CrossRef

De Beaumont L, Lassonde M, Leclerc S, Théoret H (2007) Long-term and cumulative effects of sports concussion on motor cortex inhibition. Neurosurgery 61:329-336. CrossRef

Dhanasekaran DN, Reddy EP (2008) JNK signaling in apoptosis. Oncogene 27:6245-6251. Oct 20 Medline

Eden E, Navon R, Steinfeld I, Lipson D, Yakhini Z (2009) GOrilla: a tool for discovery and visualization of enriched GO terms in ranked gene lists. BMC Bioinformatics 10:48. Feb 3 Medline

Givogri MI, de Planell M, Galbiati F, Superchi D, Gritti A, Vescovi A, et al. (2006) Notch signaling in astrocytes and neuroblasts of the adult subventricular zone in health and after cortical injury. Dev Neurosci 28:81-91. CrossRef Medline

Hansen MR, Bok J, Devaiah AK, Zha X-M, Green SH (2003) Ca2+/ calmodulin-dependent protein kinases II and IV both promote survival but differ in their effects on axon growth in spiral ganglion neurons. J Neurosci Res 72:169-184. Apr 15 CrossRef

Howe K, Clark MD, Torroja CF, Torrance J, Berthelot C, Muffato M, et al. (2013) The zebrafish reference genome sequence and its relationship to the human genome. Nature 496:498-503. Apr 25 Medline

Ishida T, Nakajima T, Kudo A, Kawakami A (2010) Phosphorylation of Junb family proteins by the Jun $\mathrm{N}$-terminal kinase supports tissue regeneration in zebrafish. Dev Biol 340:468-479. CrossRef

Iturbide A, Pascual-Reguant L, Fargas L, Cebrià JP, Alsina B, García de Herreros A, et al. (2015) LOXL2 oxidizes methylated TAF10 and controls TFIID-dependent genes during neural progenitor differentiation. Mol Cell 58:755-766. Jun 4 CrossRef

Iwata A, Browne KD, Chen X-H, Yuguchi T, Smith DH (2005) Traumatic brain injury induces biphasic upregulation of ApoE and ApoJ protein in rats. J Neurosci Res 82:103-114.
Kishimoto N, Shimizu K, Sawamoto K (2012) Neuronal regeneration in a zebrafish model of adult brain injury. Dis Model Mech 5:200209. Mar Medline

Kroehne V, Freudenreich D, Hans S, Kaslin J, Brand M (2011) Regeneration of the adult zebrafish brain from neurogenic radial glia-type progenitors. Development 138:4831-4841. Nov CrossRef

Kyritsis N, Kizil C, Zocher S, Kroehne V, Kaslin J, Freudenreich D, et al. (2012) Acute inflammation initiates the regenerative response in the adult zebrafish brain. Science 338:1353-1356. Dec 7 CrossRef

Lee JC, Schickling O, Stegh AH, Oshima RG, Dinsdale D, Cohen GM, et al. (2002) DEDD regulates degradation of intermediate filaments during apoptosis. J Cell Biol 158:1051-1066. Sep 16 Medline

Lee SW, Ko YG, Bang S, Kim KS, Kim S (2000) Death effector domain of a mammalian apoptosis mediator, FADD, induces bacterial cell death. Mol Microbiol 35:1540-1549. Mar

Len TK, Neary JP (2011) Cerebrovascular pathophysiology following mild traumatic brain injury. Clin Physiol Funct Imaging 31:85-93. Mar

Lewine JD, Davis JT, Bigler ED, Thoma R, Hill D, Funke M, et al. (2007) Objective documentation of traumatic brain injury subsequent to mild head trauma. J Head Trauma Rehab 22:141-155. May CrossRef

Lien C-L, Schebesta M, Makino S, Weber GJ, Keating MT (2006) Gene expression analysis of zebrafish heart regeneration. PLoS Biol 4:e260. Aug Medline

Lieschke GJ, Currie PD (2007) Animal models of human disease: zebrafish swim into view. Nat Rev Genet 8:353-367. May CrossRef Medline

Liu Y, Liu Z, Li X, Luo B, Xiong J, Gan W, et al. (2014) Accumulation of connective tissue growth factor + cells during the early phase of rat traumatic brain injury. Diag Pathol 9:141

Livak KJ, Schmittgen TD (2001) Analysis of relative gene expression data using real-time quantitative PCR and the 2(-Delta Delta C(T)) Method. Methods 25:402-408. Dec CrossRef Medline

Love MI, Huber W, Anders S (2014) Moderated estimation of fold change and dispersion for RNA-seq data with DESeq2. Genome Biol 15:550 Medline

Lu D, Mahmood A, Qu C, Goussev A, Schallert T, Chopp M (2005) Erythropoietin enhances neurogenesis and restores spatial memory in rats after traumatic brain injury. J Neurotrauma 22:10111017. Sep CrossRef

Lu K-T, Huang T-C, Wang J-Y, You Y-S, Chou J-L, Chan MWY, et al. (2015) NKCC1 mediates traumatic brain injury-induced hippocampal neurogenesis through CREB phosphorylation and HIF- $1 \alpha$ expression. Eur J Physiol 467:1651-1661. CrossRef

Lundin A, de Boussard C, Edman G, Borg J (2006) Symptoms and disability until 3 months after mild TBI. Brain Injury 20:799-806. CrossRef Medline

Luo Y, Zou H, Wu Y, Cai F, Zhang S, Song W (2017) Mild traumatic brain injury induces memory deficits with alteration of gene expression profile. Sci Rep 7:1077. CrossRef

Maisel M, Herr A, Milosevic J, Hermann A, Habisch H-J, Schwarz S, et al. (2007) Transcription profiling of adult and fetal human neuroprogenitors identifies divergent paths to maintain the neuroprogenitor cell state. Stem Cells 25:1231-1240. May CrossRef

Martin A, Salvador F, Moreno-Bueno G, Floristán A, Ruiz-Herguido C, Cuevas EP, et al. (2015) Lysyl oxidase-like 2 represses Notch1 expression in the skin to promote squamous cell carcinoma progression. EMBO J 34:1090-1109. Apr 15 Medline

Masel BE, DeWitt DS (2010) Traumatic brain injury: a disease process, not an event. J Neurotrauma 27:1529-1540. Aug CrossRef Medline

März M, Schmidt R, Rastegar S, Strähle U (2011) Regenerative response following stab injury in the adult zebrafish telencephalon. Dev Dyn 240:2221-2231. Aug 16 CrossRef Medline

Mckee AC, Daneshvar DH (2015) The neuropathology of traumatic brain injury. Handb Clin Neurol 127:45-66. Medline 
Miller N, Gerlai R (2012) From schooling to shoaling: patterns of collective motion in zebrafish (Danio rerio). PLoS ONE 7:e48865 Medline

Mokalled MH, Patra C, Dickson AL, Endo T, Stainier DYR, Poss KD (2016) Injury-induced ctgfa directs glial bridging and spinal cord regeneration in zebrafish. Science 354:630-634. Nov 4 Medline

Monnot MJ, Babin PJ, Poleo G, Andre M, Laforest L, Ballagny C, et al. (1999) Epidermal expression of apolipoprotein $E$ gene during fin and scale development and fin regeneration in zebrafish. Dev Dyn 214:207-215. Mar CrossRef

Mouzon BC, Bachmeier C, Ferro A, Ojo J-O, Crynen G, Acker CM, et al. (2014) Chronic neuropathological and neurobehavioral changes in a repetitive mild traumatic brain injury model. Ann Neurol 75: 241-254. Feb CrossRef

Mychasiuk R, Farran A, Angoa-Perez M, Briggs D, Kuhn D, Esser MJ (2014) A novel model of mild traumatic brain injury for juvenile rats. $J$ Vis Exp 94:1-7.

Nakagawa S, Kim J-E, Lee R, Chen J, Fujioka T, Malberg J, et al. (2002) Localization of phosphorylated cAMP response elementbinding protein in immature neurons of adult hippocampus. J. Neurosci 22:9868-9876.

Norton W, Bally-Cuif L (2010) Adult zebrafish as a model organism for behavioural genetics. BMC Neurosci 11:90 Medline

Oleinik NV, Krupenko NI, Krupenko SA (2007) Cooperation between JNK1 and JNK2 in activation of p53 apoptotic pathway. Oncogene 26:7222-7230. CrossRef

Petraglia AL, Plog BA, Dayawansa S, Dashnaw ML, Czerniecka K, Walker CT, et al. (2014) The pathophysiology underlying repetitive mild traumatic brain injury in a novel mouse model of chronic traumatic encephalopathy. Surg Neurol Int 5:184 Medline

Piya S, Kim JY, Bae J, Seol D-W, Moon AR, Kim T-H (2012) DUSP6 is a novel transcriptional target of p53 and regulates p53-mediated apoptosis by modulating expression levels of $\mathrm{Bcl}-2$ family proteins. FEBS Lett 586:4233-4240. CrossRef

Poss KD, Shen J, Keating MT (2000) Induction of lef1 during zebrafish fin regeneration. Dev Dyn 219:282-286. CrossRef Medline

Puhakka N, Bot AM, Vuokila N, Debski KJ, Lukasiuk K, Pitkänen A (2017) Chronically dysregulated NOTCH1 interactome in the dentate gyrus after traumatic brain injury. PLoS One 12:e0172521.

Raghupathi R, McIntosh TK (1996) Regionally and temporally distinct patterns of induction of c-fos, c-jun and junB mRNAs following experimental brain injury in the rat. Mol Brain Res 37:134-144. Apr Medline

Saatman KE, Duhaime A-C, Bullock R, Maas AIR, Valadka A, Manley GT, et al. (2008) Classification of traumatic brain injury for targeted therapies. J Neurotrauma 719-738. Medline

Samuels IS, Karlo JC, Faruzzi AN, Pickering K, Herrup K, Sweatt JD, et al. (2008) Deletion of ERK2 mitogen-activated protein kinase identifies its key roles in cortical neurogenesis and cognitive function. J Neurosci 28:6983-6995. Jul 2 Medline

Skaggs K, Goldman D, Parent JM (2014) Excitotoxic brain injury in adult zebrafish stimulates neurogenesis and long-distance neuronal integration. Glia 62:2061-2079. Dec Medline

Stewart AM, Braubach O, Spitsbergen J, Gerlai R, Kalueff AV (2014) Zebrafish models for translational neuroscience research: from tank to bedside. Trends Neurosci 37:264-278. May CrossRef Medline

Taylor CA, Bell JM, Breiding MJ, Xu L (2017) Traumatic brain injuryrelated emergency department visits, hospitalizations, and deaths - United States, 2007 and 2013. MMWR Surveill Summ 66:1-16. Mar 17 CrossRef

Than-Trong E, Bally-Cuif L (2015) Radial glia and neural progenitors in the adult zebrafish central nervous system. Glia 63:1406-1428. May 14 CrossRef

Vanderploeg RD, Curtiss G, Belanger HG (2005) Long-term neuropsychological outcomes following mild traumatic brain injury. J Int Neuropsychol Soc 11:228-236. CrossRef

Veth KN, Willer JR, Collery RF, Gray MP, Willer GB, Wagner DS, et al. (2011) Mutations in zebrafish Irp2 result in adult-onset ocular pathogenesis that models myopia and other risk factors for glaucoma. PLoS Genet 7:e1001310. Medline

Wang X, Mao X, Xie L, Greenberg DA, Jin K (2009) Involvement of Notch1 signaling in neurogenesis in the subventricular zone of normal and ischemic rat brain in vivo. J Cereb Blood Flow Metab 29:1644-1654. Oct Medline

Yates A, Akanni W, Amode MR, Barrell D, Billis K, Carvalho-Silva D, et al. (2016) Ensembl 2016. Nucleic Acids Res 44:D710-D716. PMCID: PMC4702834

Zhu DY, Lau L, Liu SH, Wei JS, Lu YM (2004) Activation of cAMPresponse-element-binding protein (CREB) after focal cerebral ischemia stimulates neurogenesis in the adult dentate gyrus. Proc Natl Acad Sci U S A 101:9453-9457. Jun 22 Medline 